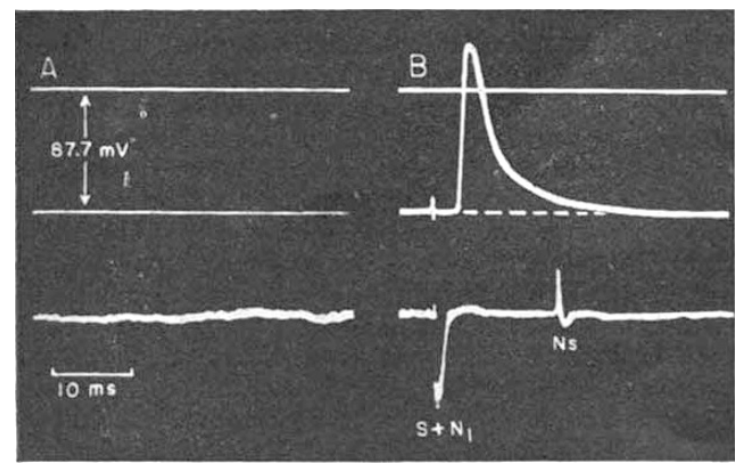

Eig. 2. Electrical activity of neuromuscular spindle. Fxtrafusal junctions blocked by curare. A single sensory unit was left intact. Upper records in $A$ and $B$, intracellular lead from a electrodes from the nerve. Simultaneous intra- and extra-cellular records.

$A$, Preparation at rest and under light tension, Resting membrane potential $87.7 \mathrm{mV}$. Lower record shows no baseline discharge. $B$, After a single nerve shock an action potential of $119.3 \mathrm{mV}$. is recorded from an intrafusal nbre. Lower record by one sensory diseharge $\left(N_{*}\right) 15 \cdot 6 \mathrm{~m}$.sec. after the shock

to the nerve produced action potentials of $84-119 \cdot 3$ $\mathrm{mV}$. and always presenting a positive overshoot of $12 \cdot 5-31 \cdot 6 \mathrm{mV}$. at $21^{\circ} \mathrm{C}$. The presence of this spike was always concomitant with an increase in the frequency of sensory discharges (Fig. 2). The characteristics of the action potential indicate that the intrafusal bundles are formed by twitch fibres, innervated by large-diameter motor axons. Nevertheless, the presence of some slow muscle fibres, innervated by the small-nerve motor system, has not been excluded.

This work was financed in part by grants from the Rockefeller Foundation (New York) and the Fundación Gildemeister (Santiago).

Laboratory of Neurophysiology and

Carlos Eyzaguirre

JUAN D. VIAI

Department of Anatomy,

Catholie University of Chile, Santiago, Chile.

April 24.

${ }^{1}$ Katz, B., J. Exp. Biol., 26, 201 (1949).

${ }^{2}$ Kuffler, S. W., Hunt, C. C., and Quilliam, J. P., J. Neurophysiol. 14, 29 (1951).

'Alexandrowicz, J. S., Quart. J. Micro. Sci., 92, 163 (1951). -Wiersma, C. A. G., Furshpan, E., and Florey, E., J. Exp. Biol., 30,
136 (1953).

'Kuffer, S. W., J. Neurophysiol., 17, 558 (1954).

- Eyzaguirre, C., and Kuffler, S. W., J. Gen. Physiol., 39, 87 (1955).

\section{Occurrence of Leuco-anthocyanin in Pears}

THE anthocyanin pigments of plants may occur in two possible colourless forms, as the pseudo-base and as leuco-anthocyanins ${ }^{1,2}$. In both cases conversion to the corresponding anthocyanin occurs on acidification, but is slower in the latter case. Although leucoanthocyanins have been isolated only from cacao beans ${ }^{3}$ and Australian heartwood of Acacia melanoxylon ${ }^{4}$ their occurrence is implied on the basis of the vanillin test and chromatographic identification of anthocyanins ${ }^{2,5}$. The occurrence of leuco-anthocyanins in pears (Pyrus communis) was suggested by Joslyn ${ }^{6}$ to explain the reddening that occurs in tinned pears stacked before they are completely cooled, and by Bate-Smith ${ }^{1}$ to explain the reddening of stewed pears. Kiesser et al. ${ }^{7}$ reported the occurrence of leucoanthocyanins in perry pears on the basis of chemical and chromatographic examination of the insoluble matter causing haze and turbidity and depositing as a sediment in perry. The red pigment obtained by treatment of the sediment with warm dilute acid was found to contain small quantities of phloroglucinoi, protocatechuic acid, catechol and cyanidin but was composed chiefly of complex leuco-anthocyanixs related to cyanidin. We have recently examined Bartlett pears for the occurrence of leuco-anthocyanins and found evidence for the presence of the leuco-anthocyanin related to cyanidin.

Halved ripe California Bartlett pears tested with vanillin reagent ${ }^{5}$ gave a strong positive test for leuco-anthocyanin in the core tissue surrounding the seeds and particularly strong reaction in the seeds. The tissue surrounding the seed receptacle gave a less intense and more diffuse reaction. For this reason, the core tissue was separated, ground and extracted first with boiling water, then with absolute methanol. The residue was then extracted with methanol con. taining 1 per cent hydrochloric acid. This extract, strongly positive to the vanillin test, was brought to 5-10 per cent hydrochloric acid and heated for 5-10 min. The red pigment so obtained was identified by paper chromatography with several solvent systems. The $R_{F}$ values obtained with butanol-acetic acid-water, butanol- $2 \mathrm{~N}$ hydrochloric acid and acetic acid-hydrochloric acid-water respectively were : $0 \cdot 24$, $0.47 ; 0.69 ; 0.49$; respectively. The $R_{F}$ values reported for cyanidin in these solvents are : 0.24 ; $0.69 ; 0.50$. Robinson's ferric chloride test was applied to extracts, in iso-amyl alcohol containing 1 per cent hydrochloric acid, of pear core tissue, after conversion to anthocyanidin by boiling with added acid. On addition of water, sodium acetate and a small amount of ferric chloride and shaking, the organic solvent layer turned blue just as cyanidin does. The anthocyanidin obtained from pear core and pear seed was stable to oxidation, as is cyanidin. The only anthocyanidin obtained from pear tissue thus is similar in $R_{F}$ value and other properties to cyanidin. M. A. JosLYN

Richard Peterson

Department of Food Technology,

University of California,

Berkeley 4, California. May 2.

1 Bate-Smith, E. C., in "Advances in Food Research", 5, 262 (ed. E. M. Mrak and G. Stewart, Academic Press, 1954). ${ }^{2}$ Geissman, J. E., in "Modern Methods of Plant Analysis", 3, 450 ${ }^{8}$ Knapp, A. W., and Hearne, J. F., Analyst, 64, 475 (1939).

4 King, F. E., and Bottomley, W., J. Chem. Soc., 1399 (1954).

${ }^{5}$ Bate-Smith, E. C., and Lerner, N. M., Biochem. J., 58, 126 (1954).

- Joslyn, M. A., Indust. Eng. Chem., 33, 308 (1941).

'Kiesser, M. E., Pollard, A., and Williams, A. H., Chem. and Indust., $1260(1953)$.

\section{Apparatus for Aeration and Sampling of Bacteria during Growth and Metabolic Studies}

The need frequently arises for the sampling of bacterial cultures during aerated growth, or of nonproliferating bacterial suspensions in the course of metabolic studies under aerated conditions. Methods requiring the use of a pipette for the withdrawal of samples are somewhat unsatisfactory because the aeration arrangements, usually capillary tubing or tubing carrying a sintered glass distributor disk, are 